\title{
Letter from the Director of the African Centre for Disaster Studies
}

The African Centre for Disaster Studies (ACDS) has come a long way since its inception in 2002. Not only has the Centre found a new home within the Research Focus Area: Sustainable Social Development, but its staff component has grown from three to nine members. The research focus of the ACDS has increased and we have been fortunate to be involved in a number of national, provincial and local projects.

One of the strategic goals of the ACDS is to engage in, and provide opportunities for dialogue in disaster risk reduction research on the continent. The establishment of the first e-journal (Jàmbá) on disaster risk reduction for Africa was one method employed to communicate new ideas and research to the broader African disaster risk reduction community. Although the e-journal lay dormant for over a year, due to financial and logistical constraints, the ACDS is proud to publish the second volume of Jàmbá in its new revised and greatly improved format. Not only will Jàmbá remain an e-journal, but it will also be available in a free printed version.

This renewal of Jàmbá would not have been possible without the partnership which the ACDS has formed with the South African National Disaster Management Centre (NDMC). The three-year financial support by the NDMC will allow us to establish Jàmbá as a peer-reviewed and accredited journal for disaster risk reduction. The association of the NDMC with the ACDS is further a clear indication of their commitment to support and encourage research in disaster risk reduction.

One of the greatest challenges still remaining, is that African scholars in the field of disaster risk do not readily publish their research and studies. We are hopeful that Jàmbá will gain momentum by attracting even more submissions from African colleagues and that we can collectively contribute to the body of disaster risk knowledge. Although Jàmbá will always have an African focus, we welcome submissions from other parts of the globe which address common issues. 
I trust that you will find this edition of Jàmbá interesting and that it will provide impetus to debate around topical disaster risk reduction issues.

\section{Prof. Dewald van Niekerk}

Director: African Centre for Disaster Studies 